Available online on 15.08.2021 at http://jddtonline.info
Open Access to Pharmaceutical and Medical Research
$\begin{gathered}\text { Copyright } \odot \text { 2021 The Author(s): This is an open-access article distributed under the terms of the CC BY-NC } 4.0 \\ \text { which permits unrestricted use, distribution, and reproduction in any medium for non-commercial use provided } \\ \text { the original author and source are credited }\end{gathered}$

Open Access Full Text Article the original author and source are credited

Review Article

\title{
Proton pump inhibitors and peptic ulcer management: Antioxidant mechanisms
}

\author{
(D) Mohanad Alfahad1,2*, (D) Mahmood H M Jasim 1,3, (D)Mohannad E Qazzaz1,4, (D)Fawaz A Alassaf1,5, \\ (iD) Mohammed N Abed ${ }^{1,3}$ \\ ${ }^{1}$ University of Mosul, College of Pharmacy, Mosul, Nineveh Province, Iraq \\ ${ }^{2}$ Department of Pharmaceutics, College of Pharmacy, University of Mosul, Mosul, Nineveh Province, Iraq \\ ${ }^{3}$ Department of Pharmaceutical Chemistry, College of Pharmacy, University of Mosul, Mosul, Nineveh Province, Iraq \\ ${ }^{4}$ Department of Pharmacognosy, College of Pharmacy, University of Mosul, Mosul, Nineveh Province, Iraq \\ ${ }^{5}$ Department of Pharmacology, College of Pharmacy, University of Mosul, Mosul, Nineveh Province, Iraq
}

Article Info:

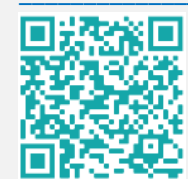

\section{Article History:}

Received 13 June 2021

Reviewed 26 July 2021

Accepted 04 Aug 2021

Published 15 August 2021

\section{Cite this article as:}

Alfahad M, Jasim MHM, Qazzaz ME, Alassaf F, Abed MN, Proton pump inhibitors and peptic ulcer management: Antioxidant mechanisms, Journal of Drug Delivery and Therapeutics. 2021; 11(4S):242-246

DOI: $h$ ttp://dx.doi.org/10.22270/jddt.v11i4-S.4955

*Address for Correspondence:

Dr. Mohanad Alfahad, Department of

Pharmaceutics, College of Pharmacy, University of

Mosul, Mosul, Nineveh Province, Iraq.

ORCID: https://orcid.org/0000-0003-0722-3066

\section{Abstract}

Peptic ulcer (P.U.) is the gastrointestinal tract's most frequent disorder affecting mainly the stomach and duodenum. Surgical intervention, ingested materials and microbial infections may trigger inflammation that further predispose to oxidative stress. Proton pump inhibitors (PPIs) are group of compounds established for suppressions of gastric acid secretions profoundly and permanently over a reasonably long period of time. Oxidative stress has been shown to be involved in the pathophysiology of various diseases and disorders, including P.U. Particularly when $H$. pylori infection accompanies it. In addition to the colonization of this microorganism, gastric mucosa may be subjected to extreme oxidative stress with large levels of inflammatory cell aggregation, which may eventually predispose to the disorder. PPIs exert several effects other than gastric acid suppression that can be used to treat Helicobacter pylori infections, disorders of the respiratory tract, viral infections, and other conditions related to dysfunction of endothelium by activating endogenous antioxidant protection and reducing the release of cytokine. Recent therapeutic protocols have recommended PPIs as gastro-protective compounds not only because of their acid suppression properties, but also because of their potent antioxidant and anti-inflammatory properties.

Keywords: Proton Pump Inhibitors, Peptic Ulcer, Oxidative Stress, H. pylori

\section{Introduction:}

Peptic ulcer (P.U.) is the gastrointestinal tract's most frequent disorder affecting mainly the stomach and duodenum. As a disease, it is characterized by an upper digestive tract mucosal lesion; including the stomach, first portion of the small intestine or even may affect the lower part of oesophagus. A stomach lesion is referred to as a gastric ulcer whereas that lesion in the lining of the first part of intestinal mucosa is known as a duodenal ulcer $\mathbf{1}$. The approximate estimated occurrence of P.U. In overall population is $5-10 \%$, with an annual incidence of $0.1-0.3 \%{ }^{2}$. Ulceration of the stomach and duodenum is often caused by acid-peptic damage to these parts of gastrointestinal tract, leading to erosion and loss mucosal lining, with eventual exposure of the gastro-dudenal underlying tissues to the digestive potential of acid and enzymes. ${ }^{3}$. The condition happens as a results of imbalance between mucosal protective and aggressive factors ${ }^{4}$, and it is now agreed that the majority of peptic ulcer cases are associated with $H$. pylori infection or the history of using non-steroidal antiinflammatory medications or both $\mathbf{5}$. Aggressive conditions that could predispose to peptic ulcer involve; pepsin, refluxed bile, hydrochloric acid (HCL), ethanol, leukotrienes (LTs), gastric cancer, and reactive oxygen species (ROS), in addition to several minor factors such as smoking, spicy food and stress. On the other hand, the defensive players include the presence of mucus-bicarbonate barrier, mucosal blood flow, prostaglandins (PGs), non-enzymatic and enzymatic antioxidants, cell renewal and migration, as well as some growth factors $\mathbf{6 , 7}$.

The chronicity and pattern of cyclic recurrence with seasonal peaks, especially during autumn and winter, have always been specific clinical features of the disease and as indicators for serious complications. The mortality rate of peptic ulcer complications, bleeding and perforation, despite the overall decline in PUD and complications, have not 
significantly improved and is still of major concern ${ }^{\mathbf{8}}$. Recent advances in understanding the pathogenesis of the disease, mainly after the reported crucial role of antioxidants as protective mediators may suggest better options for the treatment of ulcer. Proton pump inhibitors as first line medication for the treatment of P.U. have recently shown a potential antioxidant effect at variable degree which could add a beneficial dual acid suppressant and antioxidant effect to supress two main aggravating factors; acid secretion and oxidative stress. Therefore, our main goal is to review the impact of antioxidant potential of proton pump inhibitors on the management of P.U. and how these drugs could modulate the course of underlying pathology of ulcer to offer better care for patients.

\section{Peptic ulcer and oxidative stress}

The gastric mucosa plays an important role in regulating the physiological processes of the stomach. This mucous lining serves as a gastric shield, protecting the underlying tissue from the harmful activities of the components of the gastric juice and the consumed mucosal irritants. Despite the protective layer offered by the epithelial lining, surgical intervention, ingested materials (such as NSAIDs) and microbial infections, such as $H$. pylori may trigger inflammation by stimulating the epithelium, macrophages and polymorphonuclear neutrophils (PMNs), to generate some mediators including inflammatory cytokines that further predispose to oxidative stress. Numerous pathological conditions of the gastrointestinal tract including gastric or duodenal ulcers, inflammatory bowel disease and malignancies arise as a result of oxidative stress. 9 . Oxidative stress is a condition of high ROS levels that stimulates either additional development of ROS or a decrease in antioxidant capacities. 10. Under normal physiological conditions, the ROS are formed at low levels as a result of partial reduction of molecular oxygen. Reactive oxygen species, hydroxyl radical $\left(\mathrm{OH}^{\circ}\right)$, superoxide anion $\left(\mathrm{O}^{-}\right)$, singlet oxygen $\left({ }^{1} \mathrm{O}_{2}\right)$ and hydrogen peroxide (H2O2), display increased reactivity due to the presence of unpaired electron in the outer shell. However, when cells overproduce ROS more than the intrinsic antioxidant capacity, oxidative stress occurs and afterwards damage occurs in normal biomolecules of cells and tissue and essential cell components such as nucleic acids, proteins, polyunsaturated fatty acids and, to a lesser extent, carbohydrates can be attacked by reactive oxygen species $\mathbf{1 1}$.

These reactions may significantly change the intrinsic structural characteristics of the membrane such as fluidity, cell signalling, enzymatic activity, ion transport, protein crosslinking and synthesis, and eventually chromatin condensation, DNA fragmentation and cell death. 12. In general, tissue damage is mainly enhanced by peroxidation of lipids; lipid peroxides are basically metabolized to 4hydroxynonenal (4-HNE) and malondialdehyde (MDA). Reactive oxygen species-depended mucosal damage occurs when there is a boost in the level of 4-HNE and MDA. Superoxide dismutase (SOD) is regarded as the key enzyme that neutralizes ROS to result in less harmful hydrogen peroxide. Significantly reduced SOD activity is a marker of decreased protection mechanisms and contributes significantly to further cellular damage. In the presence of reduced glutathione (GSH), hydrogen peroxide is further metabolized to water. Reactive oxygen species can also be neutralized by synergistic action of GSH and SOD.
Glutathione free radical (GS.) are produced as a result of interaction ROS and GSH, these radicals can further react with GSH producing glutathione disulphide (GSSG). The latter is free radical which can then result in formation of $\mathrm{O}_{2}{ }^{-}$ by donating an electron to the oxygen that is eventually eliminated by SOD. Any reduction in the GSH activity may result in negative implications for the cellular processes of antioxidative defense. When exposed to stress factors, gastrointestinal mucosa shows an increase in lipid peroxidation (increase in 4-HNE and MDA and), and a reduction in GSH concentration and SOD activity. This stressinduced ROS signalling events seems to be a main determinant for interpreting the pathophysiology of stressinduced defects in the gastrointestinal mucosa that proceed to ulcerogenesis, with an effort to develop novel strategies for managemrnt of P.U. ${ }^{13}$.

\section{Proton pump inhibitors and antioxidant potential}

Proton pump inhibitors (PPIs) are group of compounds established in the late of the last century. Omeprazole (1) was the first of PPIs released to the markets in late 80s. Most of PPIs are benzimidazole (2) derivatives 14, esomeprazole (3), lansoprazole (4), pantoprazole (5) and rabeprazole (6) all are examples of PPIs and have the benzimidazole ring in their core structures (figure 1). Esomeprazole is a stereoisomer of omperazole. The main action of PPIs is suppressions of gastric acid secretions profoundly and permanently over a reasonably long period of time compared to other medications that inhibit acid release from the stomach 15 .

PPIs mechanism of action characterized mainly by irreversible inhibition of the enzyme system called Hydrogen/Potassium adenosine triphosphate $\left(\mathrm{H}^{+} / \mathrm{K}^{+}\right.$ ATPase), this enzyme system which is located in the gastric parietal cells act by promoting continuous proton release into the gastric lumen, this action of $\mathrm{H}^{+} / \mathrm{K}^{+}$ATPase system is the reason behind its popular name as the proton pump, the proton pumping is regarded as the final stage of the stomach acid production and inhibition of this process will provide a powerful reduction in the gastric acid content $\mathbf{1 6}$.

The PPIs are administered as prodrugs, which means in their inactive form, that need to be activated before exerting their full action. The activation process of PPIs requires a protonation step of the tertiary amines in the drug structure prior to the rearrangement step which provides the active form of the compound 17. The active drug then binds covalently and irreversibly to $\mathrm{H}^{+} / \mathrm{K}^{+}$ATPase system causing its failure to pump the protons (figure 2).

The covalent interaction between the active form of the PPI and the $\mathrm{H}^{+} / \mathrm{K}^{+}$ATPase enzyme will provide nearly a full day inhibition of gastric acid secretion. Termination of the inhibitory action of PPIs is thought to occur by reactivation of the $\mathrm{H}^{+} / \mathrm{K}^{+}$ATPase enzyme by release of the sulfide linkage between the drug and the enzyme due to the antioxidant effect of the indigenous glutathione. The inactive form of the PPIs is more lipophilic because it's neutral in charge and provides better ability for the drug to cross the lipid bilayer membrane of the cells. The plasma half-life of the PPIs is relatively short ranging between 1 and 2 hours 17 . 
<smiles>c1ccc2[nH]cnc2c1</smiles>

2<smiles>COc1ccc2[nH]c(S(=O)Cc3ncc(C)c(OC)c3C)nc2c1</smiles><smiles>COc1ccnc(CS(=O)c2nc3cc(OC(F)F)ccc3[nH]2)c1OC</smiles><smiles>COc1ccc2[nH]c(S(=O)Cc3ncc(C)c(OC)c3C)nc2c1</smiles><smiles>Cc1c(OCC(F)(F)F)ccnc1CS(=O)c1nc2ccccc2[nH]1</smiles><smiles>COCCCOc1ccnc(CS(=O)c2nc3ccccc3[nH]2)c1C</smiles>

Figure 1: Structure of proton pump inhibitors<smiles>[R]c1ccc2[nH]c(S(=O)Cc3ncc([R4])c([R9])c3[R2])nc2c1</smiles><smiles></smiles>

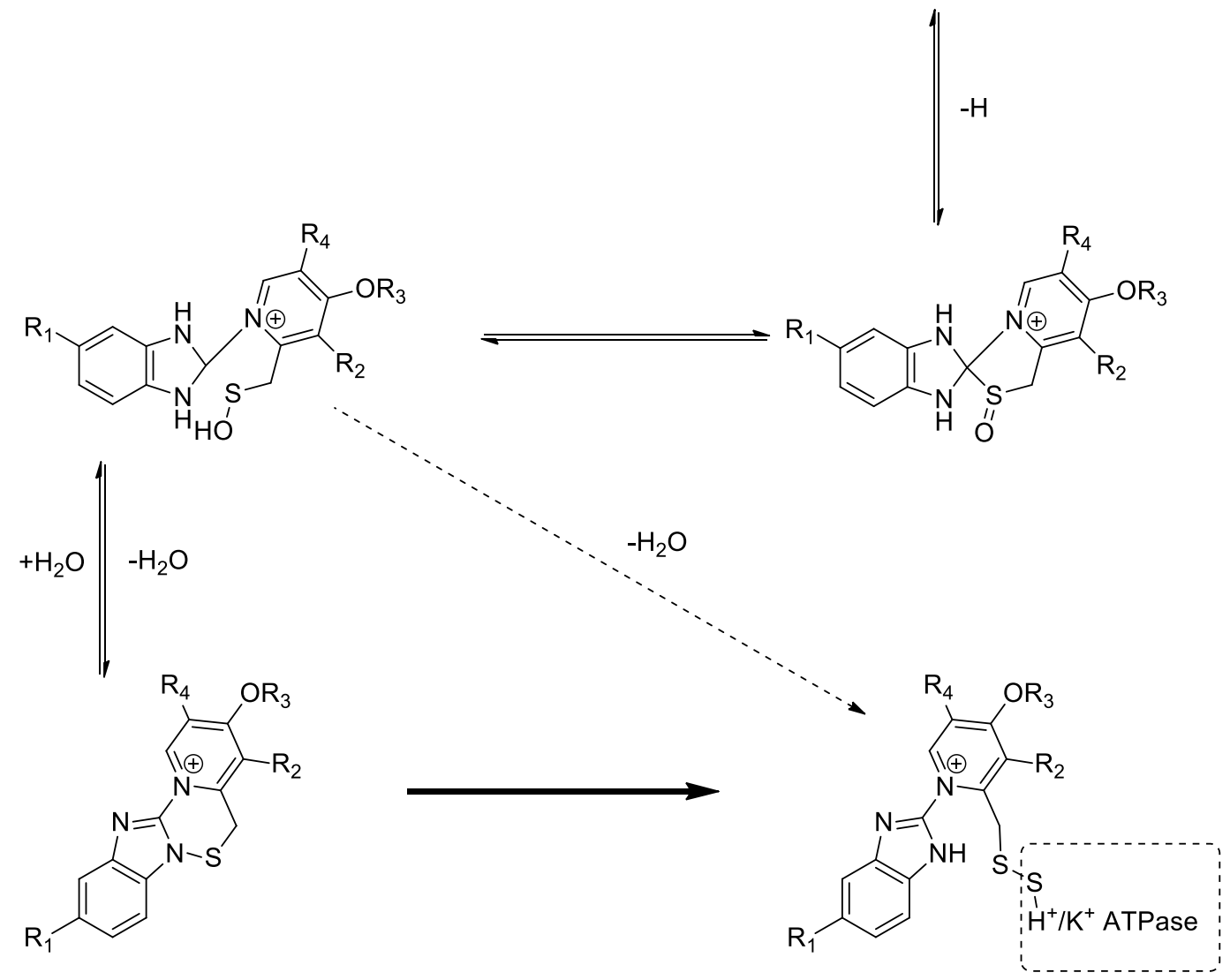

Figure 2: Schematic mechanism of action of proton pump inhibitors 
Proton pump inhibitors exert several effects that are unrelated to gastric acid suppression. They can be used to treat Helicobacter pylori infections, disorders of the respiratory tract, viral infections, tumours and also have therapeutic potential for preeclampsia, myocardial infarction and other conditions involving dysfunction of endothelium by activating endogenous antioxidant protection and reducing the release of cytokine 18-20. Based on this potential, and their ability to modify the expression of adhesion molecules, numerous reports have demonstrated that PPIs also have anti-inflammatory effects with the ability to modify the expression of adhesion molecules through direct action on inflammatory cells such as endothelial cells, neutrophils and monocytes 21,22. This potential has been agreed by Chanchal et al. who reported the potential of omeprazole (which is the prototype of PPIs) in inhibiting nuclear factor-B activation (NK-B), the release of inflammatory cytokines, and neutrophil chemotaxis. Overall, these findings indicate that omeprazole 's cellular protective role is achieved by blocking the release of proinflammatory cytokines, increasing the endogenous antioxidant defence mechanism and maintaining the integrity of the internal structure of damaged tissue 23.The severity of lesions has been shown to associate well with the elevated amount of intrinsic hydroxyl radicals that cause about $90 \%$ reduction of lesions when scavenged by dimethyl sulfoxide, suggesting that hydroxyl radicals play a significant role in gastric injury. By suppressing stress-induced elevated production of hydroxyl radicals and related protein oxidation and lipid peroxidation, omeprazole significantly blocks gastric lesions in stress and indomethacin-induced ulcers at lower doses, without inhibiting acid secretion, suggesting an independent role for its anti-ulcer activity and that its antioxidant function plays an important role in gastro-protection. Omeprazole also stops the stressinduced DNA fragmentation, reflecting its antiapoptotic role in preventing cell damage during ulceration. 24 .

The antioxidant potential of other proton pump inhibitors has been extensively studied and revealed variable results. The possible anti-fibrotic and antioxidant effect of esomeprazole in the management of liver fibrosis has been evaluated by comparing it to silymarin, a well-known hapato-protective substance. Esomeprazole improved liver integrity, reversed hepatocellular damage, decreased fibrosis scoring, corrected major histopathological abnormalities, attenuating lipid peroxidation and augmented antioxidant potential. Additionally, treatment with esomeprazole resulted in inhibition of inflammatory mediators such as TGF $\beta$, IL- 6 and TNF- $\alpha$ and retrieval of the epithelial marker e-cadherin with up-regulation of $\mathrm{Bcl}_{2}$ protein and down-regulation of hepatic Bax, which indicates its role in inhibition of tissue damage 25. Esomeprazole has also shown to have a gastro-protective role via its antioxidant activity through inhibiting the signalling pathway of NF-B and p38 MAPK. Treatment with esomeprazole also led to increased antioxidant factors expressions such as GSH and SOD and decreased MDA levels and other invasive triggers such as pepsin, gastric acid and ROS-related inflammatory damage $\mathbf{2 6}$.

The protective effect of lansoprazole on gastric ulcer and liver damage induced by oxidative stress has been studied, where pre-treatment with lansoprazole protected the stomach mucosa and liver from the oxidative damage via reduction in the level of oxidation drivers like MDA and augmentation in antioxidant parameters such as GSH, SOD, catalase, GST and glutathione 27. Likewise, Blandizzi in 2005 has explored the possible pathways of protection offered by lansoprazole against gastrointestinal damage induced by various NSAIDs in rats. The findings indicate that in addition to inhibiting gastric acid secretion, lansoprazole defense against gastric damage induced by NSAIDs depends on a decline in mucosal oxidative damage 28. Gastrointestinal blood loss occur as a result of stress-related mucosal injury, which confers the major cause of death in critically ill patients and prophylaxis with pantoprazole has shown a promising results in reducing clinically significant gastrointestinal bleedings due to its anti-inflammatory effects and antioxidant effects. ${ }^{29}$. All of the previous studies have revealed an important role for different drugs that belong to PPIs in combating oxidation which exacerbates mucosal damage in P.U. patients. However, it is still questionable whether different PPIs have similar antioxidant properties. For that, Swamy and colleagues have investigated the possible antioxidant potential of omeprazole, rabeprazole and lansoprazole and found that omeprazole has the most powerful antioxidant potential in comparison to others and was able to significantly reduce MDA level with augmentation in the activity of SOD in comparison to rabeprazole and lansoprazole ${ }^{30}$. Similarly, the possible antioxidant potential of omeprazole, esomeprazole, lansoprazole, pantoprazole has been explored and compared to help the health practitioners in suggesting a PPI that has effective antioxidant potential in addition to its acid-suppression capability. The study revealed that in comparison to drugs of the same class, omeprazole and esomeprazole may confer significant antioxidant beside their acid-suppression effect and this could add a dual protection for the gastrointestinal tract. The difference in the antioxidant potential of different PPIs was attributed to the chemical structure of these drugs, where omeprazole and esomeprazole have the strongest electron-donating groups attached to benzimidazole and pyridine moieties in comparison to others, and as such, these two agents can spare one of the unshared electrons attached to their nitrogens to react with and stabilize the free radicals ${ }^{31}$. In addition to this, the difference in antioxidant effect of various brands of esomeprazole available in community pharmacies has been investigated and revealed that different brands of the same agent may differ in their antioxidant potential and further studies are needed to address such difference 32 .

In summary, Oxidative stress has been shown to be involved in the pathophysiology of various diseases and disorders, including P.U. Particularly when $H$. pylori infection accompanies it. In addition to the colonization of this microorganism, gastric mucosa may be subjected to extreme oxidative stress with large levels of inflammatory cell aggregation, which may eventually predispose to the disorder. Recent therapeutic protocols have recommended PPIs as gastro-protective compounds not only because of their acid suppression properties, but also because of their potent antioxidant and anti-inflammatory properties. These drugs can downregulate the production of ROS to enhance anti-inflammatory or anti-oxidant performance. However, these agents may show difference in their antioxidant potential and the present studies showed that omeprazole and lansoprazole may be superior to their counterparts. In our opinion, clinical trials are needed, especially with regard to ulcer-prone populations with a high oxidative level, to investigate the potential long-term gastro-protective use of these agents.

\section{References}

[1] N. S, P. R. Introduction to PUD - A review. J Pharm Res 2017;11:878-86.

[2] Kuna L, Jakab J, Smolic R, Raguz-Lucic N, Vcev A, et al. Peptic 
Ulcer Disease: A Brief Review of Conventional Therapy and Herbal Treatment Options. J Clin Med 2019; 8:179. https://doi.org/10.3390/jcm8020179.

[3] Tarasconi A, Coccolini F, Biffl WL, Tomasoni M, Ansaloni L, et al Perforated and bleeding peptic ulcer: WSES guidelines. World J Emerg Surg 2020; 15:3. https://doi.org/10.1186/s13017-0190283-9.

[4] VOMERO ND, COLPO E. Nutritional care in peptic ulcer. ABCD Arq Bras Cir Dig (São Paulo) 2014; 27:298-302. https://doi.org/10.1590/S0102-67202014000400017.

[5] Kavitt RT, Lipowska AM, Anyane-Yeboa A, Gralnek IM. Diagnosis and treatment of peptic ulcer disease. Am J Med 2019; 132:44756. https://doi.org/10.1016/j.amjmed.2018.12.009

[6] Amandeep K, Robin S, Ramica S, Sunil K. Peptic Ulcer: a Review on Etiology and Pathogenesis. Int Res J Pharm 2012;3:34-8.

[7] Kulshreshtha M, Srivastava G, Singh M. Pathophysiological status and nutritional therapy of peptic ulcer: An update. Environ Dis 2017; 2:76. https://doi.org/10.4103/ed.ed_11_17.

[8] Malfertheiner P, Schulz C. Peptic Ulcer: Chapter Closed? Dig Dis 2020; 38:112-6. https://doi.org/10.1159/000505367.

[9] Bhattacharyya A, Chattopadhyay R, Mitra S, Crowe SE. Oxidative Stress: An Essential Factor in the Pathogenesis of Gastrointestinal Mucosal Diseases. Physiol Rev 2014; 94:32954. https://doi.org/10.1152/physrev.00040.2012.

[10] Suzuki H, Nishizawa T, Tsugawa H, Mogami S, Hibi T. Roles of oxidative stress in stomach disorders. J Clin Biochem Nutr 2012; 50:35-9. https://doi.org/10.3164/jcbn.11-115SR.

[11] Nita M, Grzybowski A. The Role of the Reactive Oxygen Species and Oxidative Stress in the Pathomechanism of the Age-Related Ocular Diseases and Other Pathologies of the Anterior and Posterior Eye Segments in Adults. Oxid Med Cell Longev 2016; 2016:1-23. https://doi.org/10.1155/2016/3164734.

[12] Priya G, Parminder N, Jaspreet S. Oxidative Stress Induced Ulcer Protected By Natural Antioxidants: a Review. Int Res J Pharm 2012; 3:76-81.

[13] Kwiecien S, Jasnos K, Magierowski M, Sliwowski Z, Pajdo R, et al. Lipid peroxidation, reactive oxygen species and antioxidative factors in the pathogenesis of gastric mucosal lesions and mechanism of protection against oxidative stress - induced gastric injury. J Physiol Pharmacol 2014; 65:613-22.

[14] Sachs G, Shin JM, Howden CW. Review article: The clinical pharmacology of proton pump inhibitors. Aliment. Pharmacol. Ther., 2006. https://doi.org/10.1111/j.13652036.2006.02943.x.

[15] Mullin JM, Gabello M, Murray LJ, Farrell CP, Bellows J, et al. Proton pump inhibitors: actions and reactions. Drug Discov Today 2009. https://doi.org/10.1016/j.drudis.2009.03.014.

[16] Shin JM, Sachs G. Pharmacology of proton pump inhibitors. Curr Gastroenterol Rep 2008; 10:528-34. https://doi.org/10.1007/s11894-008-0098-4.

[17] Shin JM, Kim N. Pharmacokinetics and pharmacodynamics of the proton pump inhibitors. J Neurogastroenterol Motil 2013. https://doi.org/10.5056/jnm.2013.19.1.25.

[18] Shoman A, Badwy A, Elhammady M, Eldesoki Y. Effect of Proton Pump Inhibitors, Vitamin E and their co- administration on heart function and Oxidative Changes in Isoprenaline Induced Myocardial Infarction in Adult Male Albino Rats. Benha Med J 2020; 0:0-0. https://doi.org/10.21608/bmfj.2020.77404.

[19] Onda K, Tong S, Beard S, Binder N, Muto M, et al. Proton Pump
Inhibitors Decrease Soluble fms-Like Tyrosine Kinase-1 and Soluble Endoglin Secretion, Decrease Hypertension, and Rescue Endothelial Dysfunction. Hypertension 2017; 69:457-68. https://doi.org/10.1161/HYPERTENSIONAHA.116.08408.

[20] Yu L-Y, Sun L-N, Zhang X-H, Li Y-Q, Yu L, et al. A review of the novel application and potential adverse effects of proton pump inhibitors. Adv Ther 2017; 34:1070-86. https://doi.org/10.1007/s12325-017-0532-9.

[21] Kedika RR, Souza RF, Spechler SJ. Potential Anti-inflammatory Effects of Proton Pump Inhibitors: A Review and Discussion of the Clinical Implications. Dig Dis Sci 2009; 54:2312-7. https://doi.org/10.1007/s10620-009-0951-9.

[22] Biswas S, Benedict SH, Lynch SG, LeVine SM. Potential immunological consequences of pharmacological suppression of gastric acid production in patients with multiple sclerosis. BMC Med 2012; 10:57. https://doi.org/10.1186/1741-7015-10-57.

[23] Chanchal SK, Mahajan UB, Siddharth S, Reddy N, Goyal SN, et al. In vivo and in vitro protective effects of omeprazole against neuropathic pain. Sci Rep 2016; 6:30007. https://doi.org/10.1038/srep30007.

[24] Biswas K, Bandyopadhyay U, Chattopadhyay I, Varadaraj A, Ali E, et al. A Novel Antioxidant and Antiapoptotic Role of Omeprazole to Block Gastric Ulcer through Scavenging of Hydroxyl Radical. J Biol Chem 2003; 278:10993-1001. https://doi.org/10.1074/jbc.M210328200.

[25] Eltahir HM, Nazmy MH. Esomeprazole ameliorates CCl4 induced liver fibrosis in rats via modulating oxidative stress, inflammatory, fibrogenic and apoptotic markers. Biomed Pharmacother 2018; 97:1356-65. https://doi.org/10.1016/j.biopha.2017.11.028.

[26] Xie W, Huang X, Chen R, Chen R, Li T, et al. Esomeprazole alleviates the damage to stress ulcer in rats through not only its antisecretory effect but its antioxidant effect by inactivating the p38 MAPK and NF- $\kappa$ B signaling pathways. Drug Des Devel Ther 2019; 13:2969-84. https://doi.org/10.2147/DDDT.S193641.

[27] Agnihotri N, Kaur H, Kaur N, Sarotra P. Role of oxidative stress in lansoprazole-mediated gastric and hepatic protection in Wistar rats. Indian J Gastroenterol 2007; 26:118-21.

[28] Blandizzi C. Lansoprazole prevents experimental gastric injury induced by non-steroidal anti-inflammatory drugs through a reduction of mucosal oxidative damage. World J Gastroenterol 2005; 11:4052. https://doi.org/10.3748/wjg.v11.i26.4052.

[29] Tabeefar H, Beigmohammadi MT, Javadi MR, Abdollahi M, Mahmoodpoor A, et al. Effects of Pantoprazole on Systemic and Gastric Pro- and Anti-inflammatory Cytokines in Critically Ill Patients. Iran J Pharm Res IJPR 2012; 11:1051-8. https://doi.org/10.22037/ijpr.2012.1196.

[30] Swamy AHMV, Thippeswamy AHM, Sadiq A, Sajjan M, Koti B. Influence of proton pump inhibitors on dexamethasone-induced gastric mucosal damage in rats. Indian J Pharm Sci 2011; 73:193-8. https://doi.org/10.4103/0250-474X.91582.

[31] Abed MN, Alassaf FA, Jasim MHM, Alfahad M, Qazzaz ME. Comparison of Antioxidant Effects of the Proton PumpInhibiting Drugs Omeprazole, Esomeprazole, Lansoprazole, Pantoprazole, and Rabeprazole. Pharmacology 2020:1-7. https://doi.org/10.1159/000506232.

[32] Alfahad M, Qazzaz ME, Abed MN, Alassaf FA, Jasim MHM. Comparison of Anti-Oxidant Activity of Different Brands of Esomeprazole Available in Iraqi Pharmacies. Syst Rev Pharm 2020; 11:330-4. https://doi.org/10.31838/srp.2020.5.48. 